\title{
REMOVED: Anterior mediastinal cholesterol granuloma - A case report
}

\author{
Bulungo Florah Mwilambwe ${ }^{1}$, Sonu Nigam ${ }^{1}$, Sylvio Provenzano ${ }^{2}$ \\ ${ }^{1}$ Department of Anatomical Pathology, Pathology Queensland, Gold Coast University Hospital, Gold Coast, \\ Qld, Australia \\ ${ }^{2}$ Department of Cardiothoracic Surgery, Gold Coast University Hospital, Gold Coast, Qld, Australia
}

This article has been removed: please see Elsevier Policy on Article Withdrawal (https://www.elsevier.com/ about/our-business/policies/article-withdrawal).

This article has been removed at the request of the Authors and the Editor in Chief due to patient consent issues. 